\title{
Non-Heme Iron Catalysts with a Rigid Bis-Isoindoline Backbone and Their Use in Selective Aliphatic $\mathrm{C}-\mathrm{H}$ Oxidation
}

\author{
Jianming Chen, ${ }^{\mathrm{a}}$ Martin Lutz, ${ }^{\mathrm{b}}$ Michela Milan, ${ }^{\mathrm{c}}$ Miquel Costas, ${ }^{\mathrm{c}}$ Matthias Otte, ${ }^{\mathrm{a}}$ \\ and Robertus J. M. Klein Gebbink ${ }^{\mathrm{a}, *}$ \\ a Organic Chemistry \& Catalysis, Debye Institute for Nanomaterials Science, Utrecht University, Universiteitsweg 99, 3584 \\ CG Utrecht, The Netherlands \\ E-mail: r.j.m.kleingebbink@uu.nl \\ b Crystal and Structural Chemistry, Bijvoet Center for Biomolecular Research, Utrecht University, Padualaan 8, $3584 \mathrm{CH}$ \\ Utrecht, The Netherlands \\ c Institut de Química Computacional i Catàlisi (IQCC) and Departament de Química, Universitat de Girona, Campus \\ Montilivi, E-17071 Girona, Catalonia, Spain
}

Received: February 26, 2017; Revised: May 31, 2017; Published online: June 28, 2017

Supporting information for this article is available on the WWW under https://doi.org/10.1002/adsc.201700239

\begin{abstract}
Iron complexes derived from a bis-isoindoline-bis-pyridine ligand platform based on the $\mathrm{BPBP}$ ligand $\left(\mathrm{BPBP}=N, N^{\prime}\right.$-bis(2-picolyl)-2,2'-bispyrrolidine) have been synthesized and applied in selective aliphatic $\mathrm{C}-\mathrm{H}$ oxidation with hydrogen peroxide under mild conditions. The introduction of benzene moieties on the bis-pyrrolidine backbone leads to an increased preference of tertiary over secondary $\mathrm{C}-\mathrm{H}$ bond oxidation $\left(3^{\circ} / 2^{\circ}\right.$ ratio up to 33 ). On the other hand, substituting the metaposition of the pyridines with bulky silyl groups affords enhanced secondary $\mathrm{C}-\mathrm{H}$ oxidation selectivity and generally leads to higher product yields and mass balances.
\end{abstract}

Keywords: bioinspired catalysis; $\mathrm{C}-\mathrm{H}$ oxidation; hydrogen peroxide; iron; product selectivity

Oxidation of aliphatic $\mathrm{C}-\mathrm{H}$ groups is of particular interest in organic synthesis due to the large abundance of aliphatic moieties in natural products and petrochemical platform molecules, as well as the added value of their corresponding hydroxyl and carbonyl compounds. ${ }^{[1]}$ To date, a vast number of ironcontaining enzymes, such as methane monooxygenase (MMO) and $\alpha$-ketoglutarate- $(\alpha-K G)$-dependent dioxygenases, have been revealed to perform biological $\mathrm{C}-\mathrm{H}$ oxidations through the activation of dioxygen in a selective manner. ${ }^{[2]}$ Inspired by these enzymes, the past decades have witnessed the development of a variety of biomimetic non-heme iron catalysts. ${ }^{[3]}$ In $1997,{ }^{[4]}$ a synthetic Fe coordination complex was firstly demonstrated to be capable of stereospecific alkane hydroxylation by Que and co-workers, where the tetradentate N-donor ligand TPA (tris(2-pyridylmethyl)amine) was employed and $\mathrm{H}_{2} \mathrm{O}_{2}$ was used as terminal oxidant. Since then, several Fe complexes based on tetradentate N4 ligands have been developed. ${ }^{[5]}$ Amongst them, iron complexes featuring bisalkylamine-bis-pyridine (N2Py2) ligands have been proven to be the most effective ${ }^{[6]}$ Modifications of this ligand platform often ended up with lower efficiency. ${ }^{[6]}$ These studies were mainly done under large excess of substrate and had limited interest from a synthetic perspective. However, in 2007, ${ }^{[7]}$ White and co-workers described catalytic oxidations under substrate limiting conditions. In this work, a ligand modification strategy was introduced that rigidifies the bis-alkylamine backbone by incorporating the alkylamines into pyrrolidines, forming the BPBP ligand $\left(\mathrm{BPBP}=N, N^{\prime}-\right.$ bis(2-picolyl)-2,2'-bis-pyrrolidine; Figure 1, left), which translated into improved product selectivities. ${ }^{[7]}$ A

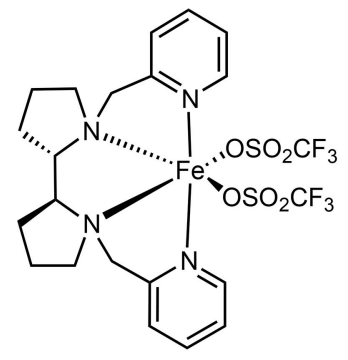

$(S, S)-\left[\mathrm{Fe}(\mathrm{BPBP})(\mathrm{OTf})_{2}\right]$ 1

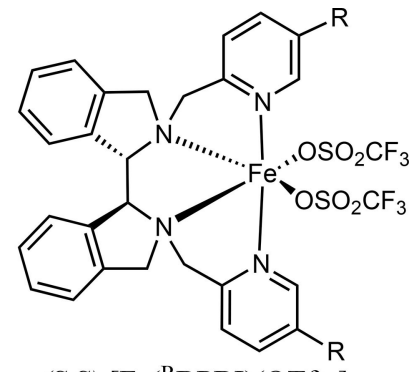

$(S, S)-\left[\mathrm{Fe}\left({ }^{\mathrm{R}} \mathrm{BPBI}\right)(\mathrm{OTf})_{2}\right]$

2: $\mathrm{R}=\mathrm{H}$

3: $\mathrm{R}=\mathrm{TIPS}$
Figure 1. Complexes 1-3 studied in this work. 
similar strategy was adopted by Rybak-Akimova and co-workers, where they rigidified the alkylamine moiety into 6-membered piperidine rings. ${ }^{[8]}$ Many efforts have been spent on the modification of the pyridine moieties as well. ${ }^{[9]}$ We have recently reported that the introduction of bulky TIPS (tris-(isopropyl)silyl) groups at the meta-position of the pyridine rings will lead to increased secondary $\mathrm{C}-\mathrm{H}$ oxidation and improved mass balance. ${ }^{[10]}$ Through this modification, site-selective methylene oxidation of steroidal substrates has also been achieved.

With the goal of achieving enhanced $\mathrm{C}-\mathrm{H}$ oxidation selectivities, herein we report iron complex $(S, S)$ $\left[\mathrm{Fe}(\mathrm{BPBI})(\mathrm{OTf})_{2}\right] \quad$ (2) $\quad\left(\mathrm{BPBI}=\left(N, N^{\prime}\right.\right.$-bis $(2$-picolyl $)$ $2,2^{\prime}$-bis-isoindoline) and its TIPS substituted analogue $(S, S)-\left[\mathrm{Fe}\left({ }^{\mathrm{TIPS}} \mathrm{BPBI}\right)(\mathrm{OTf})_{2}\right] 3$ (Figure 1), which bear a further rigidified bis-isoindoline backbone compared to the bis-pyrrolidine in the BPBP ligand. We have found that the BPBI complex 2 gives rise to higher tertiary over secondary $\mathrm{C}-\mathrm{H}$ oxidation selectivities than the parent complex $(S, S)-\left[\mathrm{Fe}(\mathrm{BPBP})(\mathrm{OTf})_{2}\right](\mathbf{1})$. On the other hand, $\mathbf{3}$ exhibits enhanced secondary $\mathrm{C}-\mathrm{H}$ oxidation ability and increased product yields.

The chiral $(S, S)$-bis-isoindoline backbone of the BPBI ligand was prepared according to a previously reported procedure. ${ }^{[1]]}$ It was readily converted into target complexes $\mathbf{2}$ and $\mathbf{3}$ by alkylation with 2-picolyl chloride derivatives and subsequent complexation with $\mathrm{Fe}(\mathrm{OTf})_{2} \cdot 2 \mathrm{CH}_{3} \mathrm{CN}$ (see Supporting Information for experimental details). Figure 2 shows the X-ray crystal structures of complexes $\mathbf{2}$ and $\mathbf{3}$. The absolute structure of the two complexes was proven by the Flack parameter (see Supporting Information) and similarly to $\mathbf{1}$, they also feature a cis- $\alpha$ coordination topology, which has been shown a crucial factor for good catalytic efficiency in previous studies. ${ }^{[12]}$ In complex $\mathbf{3}$, the installation of bulky TIPS groups on
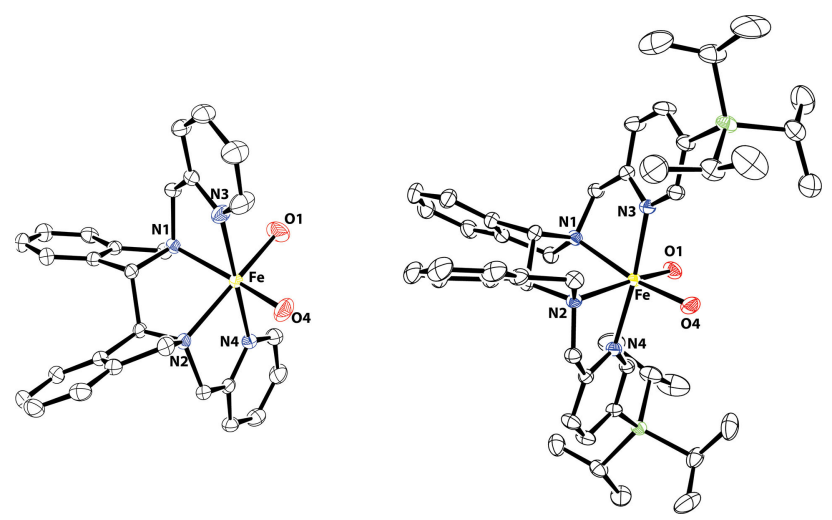

Figure 2. Molecular structures of $\mathbf{2}$ (left) and $\mathbf{3}$ (right) in the crystal, drawn at the $50 \%$ probability level. ${ }^{[13]}$ Only the coordinated $\mathrm{O}$ atoms of the triflate groups are shown. Hydrogen atoms, solvent molecules and the second independent molecule of $\mathbf{3}$ are omitted for clarity. the two pyridines leads to a crowded envelope-like configuration around the cis labile positions of the iron center ${ }^{[10]}$ (Figure 2, right, also see Figure S3), where the plausible reactive $\mathrm{Fe}$-oxo species that is responsible for site selective $\mathrm{C}-\mathrm{H}$ oxidation is generated. ${ }^{[14]}$ In this sense, the bulky nature may result in modulated regioselectivity. Only slight differences are seen between complexes 1-3 for the bond lengths and angles of the $\mathrm{Fe}$ coordination environment. Selected bond lengths and angles for $(R, R)-\mathbf{1}^{[15]}(S, S)-\mathbf{2}$ and $(S, S)-\mathbf{3}$ are listed in Table S1. As expected, the FeN(pyridine) distances (2.1390(4)-2.192(3) $\AA$ ) are shorter than the $\mathrm{Fe}-\mathrm{N}$ (amine) distances of 2.199(3)2.2249(14) $\AA$. This difference is more distinct in $\mathbf{2}$ and 3 compared to 1. Overall, these long $\mathrm{Fe}-\mathrm{N}$ distances are consistent with high-spin Fe(II) complexes. ${ }^{[12 b, 16]}$ The main differences in the crystal structures are found for the orientation of the triflate ligands. Slightly smaller O-Fe-O angles in 3 (100.17(6) and $\left.100.56(6)^{\circ}\right)$ are observed compared to $2\left(102.49(15)^{\circ}\right)$, which might be due to the larger steric demand of the ligand in $\mathbf{3}$; the smallest $\mathrm{O}-\mathrm{Fe}-\mathrm{O}$ angle is found in $\mathbf{1}$. A quaternion fit of $\mathbf{1}$ and $\mathbf{2}$ clearly shows that the BPBP and BPBI ligands provide a very similar steric environment around the iron center (see Figure S4 in Supporting Information). Interestingly, ${ }^{1} \mathrm{H}$ NMR spectra of complex $\mathbf{2}$ and $\mathbf{3}$ show a single paramagnetic species (see Supporting Information), indicating that these complexes have a high-spin state in solution and that the $\mathrm{C}_{2}$ symmetric structure of the complexes is retained in solution. Cyclic voltammetry measurements showed that $\mathbf{2}$ and $\mathbf{3}$ have very similar $\mathrm{Fe}(\mathrm{II}) /$ $\mathrm{Fe}(\mathrm{III})$ potentials $\left(\mathrm{E}_{1 / 2}=0.82,0.81 \mathrm{~V}\right.$, respectively; see Figure S5 in Supporting Information). These values are somewhat more positive than that of $\mathbf{1}\left(\mathrm{E}_{1 / 2}=\right.$ $0.70 \mathrm{~V}$ ), which is likely due to the electron-withdrawing properties of the benzene rings in the BPBI ligand.

With $\mathbf{2}$ and $\mathbf{3}$ in hand we investigated their ability to catalyse the oxidation of aliphatic $\mathrm{C}-\mathrm{H}$ bonds. To do so, a set of substrates consisting of cyclohexane (4), cis-1,2-dimethylcyclohexane (7), trans-1,2-dimethylcyclohexane (11), trans-decalin (15), adamantane (19), L-(-)-menthyl acetate (23) and methyl hexanoate (26) has been studied. For comparison purposes, complex 1 bearing the structurally related BPBP ligand was also tested.

Using $1.0 \mathrm{~mol} \%$ catalyst loading, cyclohexane (4) is oxidized to cyclohexanone (5) and cyclohexanol (6) in the presence of 1.2 equiv. $\mathrm{H}_{2} \mathrm{O}_{2}$ and 0.5 equiv. acetic acid in $\mathrm{CH}_{3} \mathrm{CN}$ at $0^{\circ} \mathrm{C}$. For all three catalysts, 5 is formed as the major product ( 5 is formed through oxidation of initially generated $\mathbf{6}$ due to the substrate limiting reaction conditions). Reaction with $\mathbf{1}$ gives a higher ketone to alcohol (K/A) ratio compared to 2 (7.0 over 1.5, Table 1 ). With $\mathbf{3}$ a medium K/A ratio (4.0) was observed, albeit with the highest substrate 
conversion and mass balance amongst the three complexes (64\% and 53\%, respectively).

Table 1. Cyclohexane Oxidation by $\mathbf{1}, \mathbf{2}$ and 3. ${ }^{[a]}$

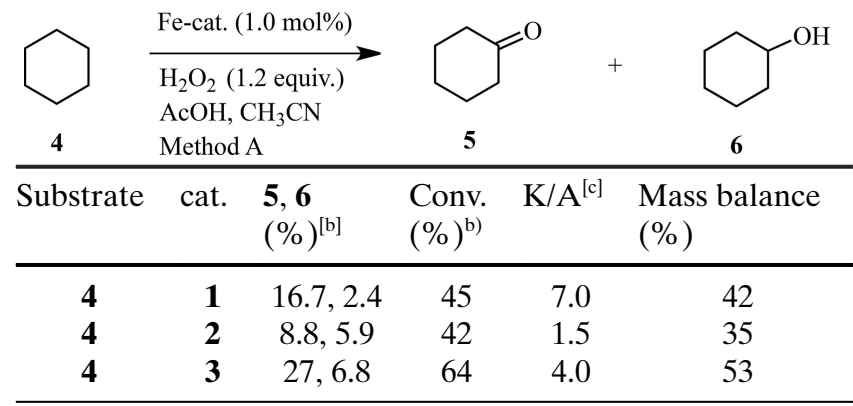

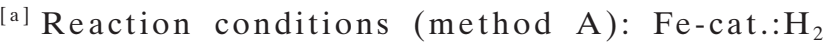
$\mathrm{O}_{2}$ :substrate: $\mathrm{AcOH}=1: 120: 100: 50, \quad 0^{\circ} \mathrm{C}$, oxidant added by syringe pump over $6 \mathrm{~min}$, and reaction mixture stirred for additional $10 \mathrm{~min}$.

${ }^{[b]}$ Determined by GC analysis.

${ }^{[c]}$ Ketone/alcohol ratio $=\mathbf{5} / \mathbf{6}$.

The ability of these complexes to discriminate between tertiary and secondary $\mathrm{C}-\mathrm{H}$ bonds is illustrated by the $3^{\circ} / 2^{\circ}$ ratios in the oxidation of $\mathbf{7 , 1 1}, \mathbf{1 5}$ and 19, which have multiple secondary and tertiary $\mathrm{C}-\mathrm{H}$ sites (Table 2). Oxidation of $\mathbf{7}$ catalyzed by $\mathbf{1}$ generates $3^{\circ}$ oxidation product 8 as the major product with $2^{\circ}$ oxidation products $\mathbf{9}$ and $\mathbf{1 0}$ as minor products, affording a $3^{\circ} / 2^{\circ}$ ratio of 7.0 . The corresponding $3^{\circ} / 2^{\circ}$ ratio was found to increase to 8.8 when changing the catalyst to 2 , along with the decrease in conversion from $61 \%$ to $32 \%$ (Table 2). The oxidation of tertiary over secondary $\mathrm{C}-\mathrm{H}$ bonds is less preferential when performing this reaction with $\mathbf{3}$ (with a value of 4.6, Table 2). This observation is consistent with our previous study, which showed that the introduction of bulky TIPS groups can lead to an enhanced methylene oxidation selectivity, because oxidation of sterically more congested tertiary $\mathrm{C}-\mathrm{H}$ bonds is disfavored. ${ }^{[10]}$ Similarly, a slightly higher $3^{\circ} / 2^{\circ}$ ratio (1.4) is found for $\mathbf{2}$ in the oxidation of $\mathbf{1 1}$ than for $\mathbf{1}(1.0)$. Much more secondary oxidized products are formed in the reaction catalyzed by 3 , giving a $3^{\circ} / 2^{\circ}$ ratio of 0.3 .

Similar catalytic outcomes were found in the oxidations of $\mathbf{1 5}$ and $\mathbf{1 9}$ in the presence of 1-3. The tertiary $\mathrm{C}-\mathrm{H}$ oxidation products are more preferentially formed in the reactions with $\mathbf{2}$ than in the cases of $\mathbf{1}$ and $\mathbf{3}$, with a $3^{\circ} / 2^{\circ}$ ratio of 0.35 in the case of $\mathbf{1 5}$ and 33 in the case of $\mathbf{1 9}$ (Table 2). Notably, the latter ratio is amongst the highest reported $3^{\circ} / 2^{\circ}$ selectivities for non-heme $\mathrm{Fe}$ catalyzed adamantane oxidation. ${ }^{[3 a, 17]}$ The lowest $3^{\circ} / 2^{\circ}$ ratios $(0.07$ and 16 , respectively) were observed for complex $\mathbf{3}$, further supporting the enhanced ability of $\mathbf{3}$ to catalyze secondary $\mathrm{C}-\mathrm{H}$ oxidations. For the reactions in Table 2, 3 stands out
Table 2. Oxidation of substrates 7, 11, 15 and $19 .{ }^{[a]}$

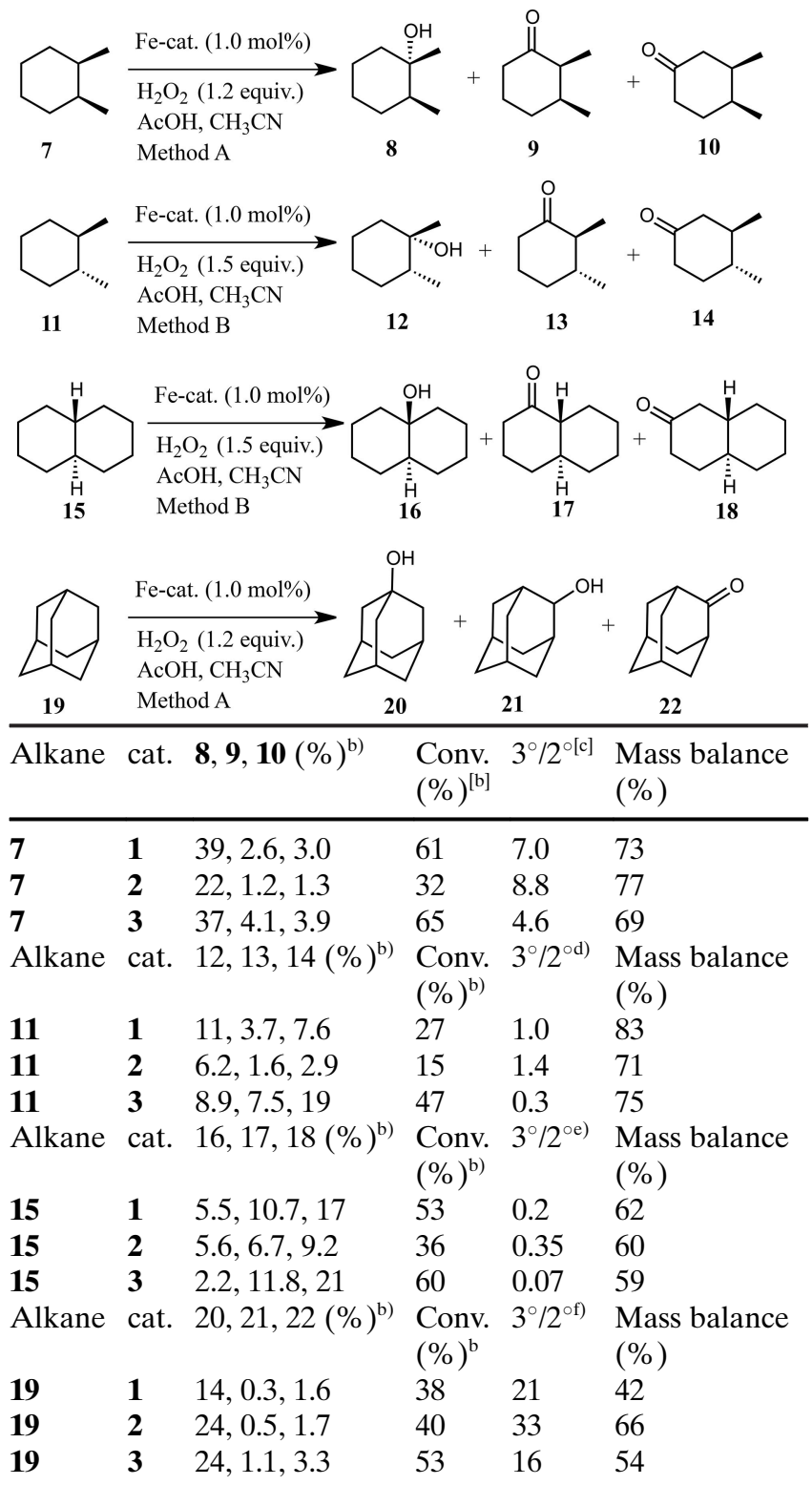

${ }^{\text {[a] }}$ For substrate $\mathbf{7}$ and $\mathbf{1 9}$, method $\mathrm{A}$ is used. For substrate $\mathbf{1 1}$ and 15, method B is used: Fe-cat.: $\mathrm{H}_{2} \mathrm{O}_{2}$ :substrate: $\mathrm{AcOH}=$ 1:150:100:50, $0^{\circ} \mathrm{C}$, oxidant added by syringe pump over 30 min, and reaction mixture stirred for additional $1.5 \mathrm{~h}$.

${ }^{[b]}$ Determined by GC analysis.

[c] $3^{\circ} / 2^{\circ}=\mathbf{8} /(\mathbf{9}+\mathbf{1 0})$.

[d] $3^{\circ} / 2^{\circ}=\mathbf{1 2} /(\mathbf{1 3}+\mathbf{1 4})$

[e] $3^{\circ} / 2^{\circ}=\mathbf{1 6} /(\mathbf{1 7}+\mathbf{1 8})$

[f] $3^{\circ} / 2^{\circ}=3 \times \mathbf{2 0} /(\mathbf{2 1}+\mathbf{2 2})$.

amongst the three complexes with the highest conversions.

The oxidations of unfunctionalized aliphatic alkanes 4, 7, 11, 15 and 19 give different outcomes, responding to the structural changes in complexes 1-3. The change in ligand backbone from bis-pyrrolidine in $\mathbf{1}$ to more rigid bis-isoindoline in $\mathbf{2}$ gives rise to a 
higher alcohol selectivity (Table 1 ) and improved $3^{\circ} / 2^{\circ}$ ratios (Table 2). On the contrary, enhanced selectivities for methylene are achieved when $\mathbf{3}$ is applied. These observations stimulated our interest in the oxidation of functionalized aliphatic substrates.

To probe the steric effect on the oxidation site selectivity, the oxidation of $\mathrm{L}-(-)$-menthyl acetate (23), containing two tertiary $\mathrm{C}-\mathrm{H}$ bonds (both at a $\gamma$ position to the acetoxy group) with different steric environments, by complexes 1-3 was examined (Table 3). The lower steric hindrance hydroxylation product $\mathbf{2 4}$ was preferentially formed in the oxidation of 23 for all catalysts tested, indicating that these reactions in the presence of $\mathbf{1}-\mathbf{3}$ are sensitive to steric factors. No difference in the preference of formation of $\mathbf{2 4}$ were observed, i.e., in all the cases, $\mathbf{2 4 / 2 5}$ ratios around 5.4 were found (Table 3 ). In terms of conversion and mass balance, 3 outperformed the other catalysts.

Table 3. Oxidation of substrate 23 and 26 by $\mathbf{1}, \mathbf{2}$ and $\mathbf{3}^{[\mathrm{a}]}$

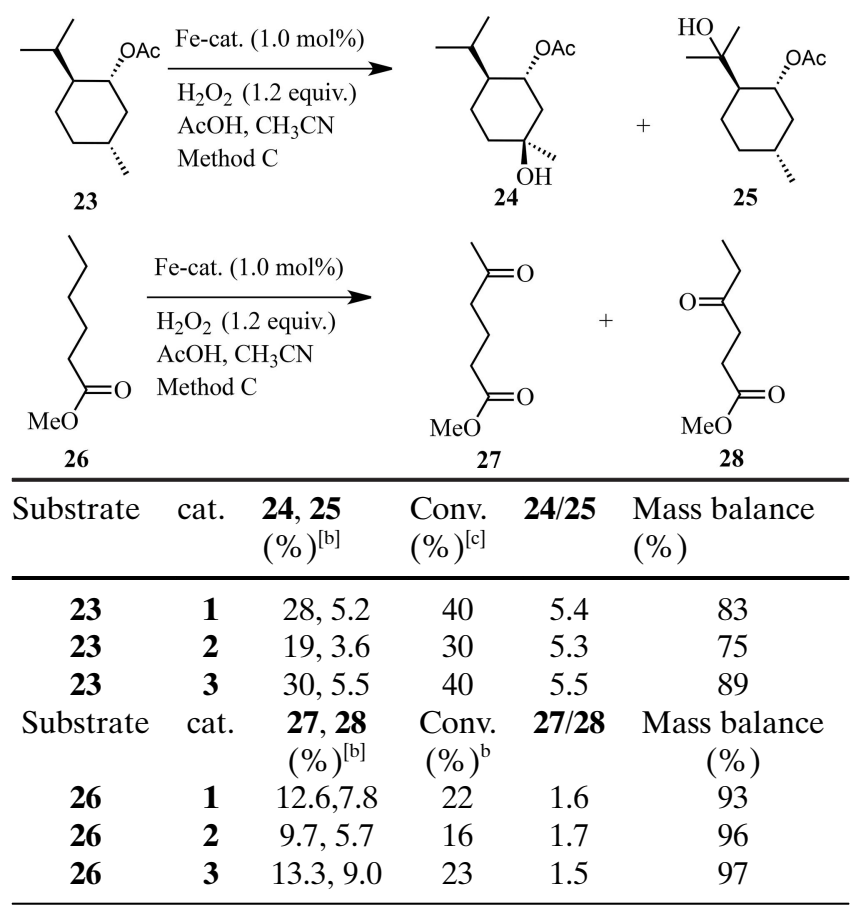

[a] Reaction conditions (method C): Fe-cat.: $\mathrm{H}_{2}$ $\mathrm{O}_{2}$ :substrate: $\mathrm{AcOH}=1: 120: 100: 50, \quad 0^{\circ} \mathrm{C}$, oxidant added by syringe pump over $0.5 \mathrm{~h}$, and reaction mixture stirred for additional $2 \mathrm{~h}$.

${ }^{[b]}$ Determined by NMR analysis.

Methyl hexanoate (26), containing an electronwithdrawing ester-group, was tested in order to look into electronic influences on site selectivity. It was found that the change in catalyst has nearly no effect on the ratios of $\delta$-oxidized product (27) to $\gamma$-oxidized product (28) in the oxidation of $\mathbf{2 6}$ (all are around 1.6,
Table 3). Notably, excellent mass balances were observed in all cases (93\%-97\%), with 3 again showing the highest product formation.

Next, we turned to investigate the catalytic performance of $\mathbf{2}$ and $\mathbf{3}$ on elaborated steroidal substrates 29 and 30 (Scheme 1). These structurally complex compounds are ideal substrates to investigate siteselective $\mathrm{C}-\mathrm{H}$ oxidation due to the multiple secondary and tertiary $\mathrm{C}-\mathrm{H}$ groups. Steroids are of particular interest because of their importance in drug discovery $^{[18]}$ and their various physical and biological properties based on the different oxidation patterns. ${ }^{[19]}$
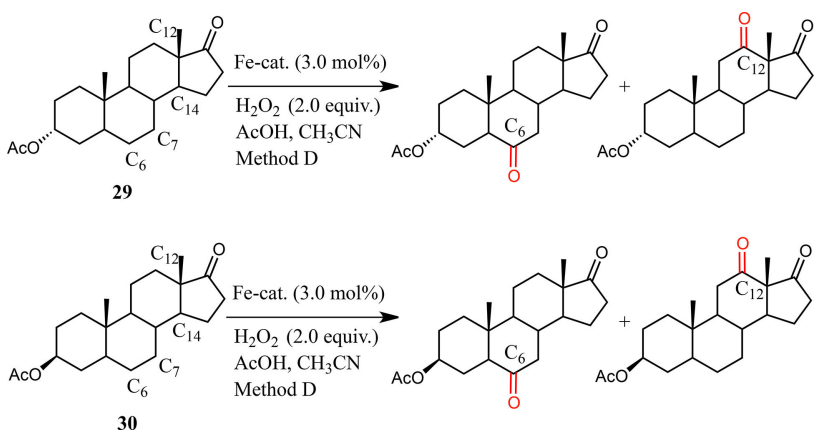

Scheme 1. Catalytic Oxidation of cis-acetylandrosterone acetate (29) and trans-acetylandrosterone acetate (30).

Oxidation of $\mathbf{2 9}$ and $\mathbf{3 0}$ was performed with $3 \mathrm{~mol} \% \mathrm{Fe}$ catalyst, $200 \mathrm{~mol} \% \mathrm{H}_{2} \mathrm{O}_{2}$ and $150 \mathrm{~mol} \%$ $\mathrm{AcOH}$ at $0{ }^{\circ} \mathrm{C}$. Poor yields and mass balances were obtained when $\mathbf{2}$ was employed in both reactions and site selectivities could not be estimated in these cases (Table 4). Yields and mass balances increased responding to the steric bulk of catalyst 3. For both substrates, the C6 oxidized ketone is preferentially formed ( $58 \%$ and $72 \%$ selectivity, respectively), with C7 and C12 oxidized ketones as minor products. Of note is that these observations support the importance of bulky silyl moieties on the ligand for achieving siteselective oxidations of acetylandrosterone derivatives. $^{[10]}$ In previous studies, 1 gave poor C6 over $\mathrm{C} 12$ selectivity, ${ }^{[20]}$ while $49-82 \%$ selectivity for C6 oxidation was obtained in the cases of the corresponding TIPS-substituted 1. ${ }^{[10]}$

In conclusion, we have described the use of bioinspired iron complexes based on an N2Py2 ligand platform bearing a bis-isoindoline backbone in selective aliphatic $\mathrm{C}-\mathrm{H}$ oxidations. Compared to parent complex 1, complex $\mathbf{2}$ shows preference for tertiary over secondary $\mathrm{C}-\mathrm{H}$ bond oxidation for alkane substrates. The catalytic performance of $\mathbf{3}$ provides further experimental evidence that bulky TIPS groups on meta-positions of the pyridine moieties enhance secondary $\mathrm{C}-\mathrm{H}$ bond oxidations and site-selective oxidations of acetylandrosterone derivatives. ${ }^{[10]} \mathrm{We}$ 
Table 4. Oxidation of steroidal substrates by 2 and 3. ${ }^{[a]}$

\begin{tabular}{lllll}
\hline Steroid & cat. & $\begin{array}{l}\text { Conv. } \\
(\%)^{\mathrm{b})}\end{array}$ & $\begin{array}{l}\mathrm{C}_{6} / \mathrm{C}_{7} / \mathrm{C}_{14} \\
(\%)^{[\mathrm{b}]}\end{array}$ & $\begin{array}{l}\text { Norm. yield } \\
\mathrm{C}_{6} / \mathrm{C}_{7} / \mathrm{C}_{12} \\
(\%)\end{array}$ \\
\hline $\mathbf{2 9}$ & $\mathbf{2}$ & 31 & $4 / 3 / 2$ & \\
$\mathbf{2 9}$ & $\mathbf{3}$ & 31 & $\begin{array}{l}11 / 5 / 3 \\
\mathrm{C}_{6} / \mathrm{C}_{7} / \mathrm{C}_{12} / \mathrm{C}_{14}\end{array}$ & $\begin{array}{l}58 / 26 / 18 \\
(\%)\end{array}$ \\
Steroid & cat. & $\begin{array}{l}\text { Conv. yield } \\
(\%)^{[b]}\end{array}$ & $\begin{array}{l}\mathrm{C}_{6} / \mathrm{C}_{7} / \mathrm{C}_{12} / \mathrm{C}_{14} \\
(\%)\end{array}$ \\
$\mathbf{3 0}$ & $\mathbf{2}$ & 23 & $5 / 1 / 1 / 5$ & \\
$\mathbf{3 0}$ & $\mathbf{3}$ & 38 & $23 / 4 / 4 / 1$ & $72 / 13 / 13 / 2$
\end{tabular}

[a] Reaction conditions (method D): Fe-cat.: $\mathrm{H}_{2}$ $\mathrm{O}_{2}$ :substrate: $\mathrm{AcOH}=3: 200: 100: 150,0^{\circ} \mathrm{C}$, oxidant added by syringe pump over $30 \mathrm{~min}$, and reaction mixture stirred for additional $10 \mathrm{~min}$.

${ }^{[b]}$ Determined by GC analysis.

believe that the incorporation of a bis-isoindoline backbone provides an additional means of modification of the popular BPBP ligand in oxidation catalysis. Further modification on the aromatic rings of the chiral BPBI backbone may offer a versatile and alternative strategy for ligand design in N2Py2-based iron complexes. We are currently exploring such ligand modifications in catalytic $\mathrm{C}-\mathrm{H}$ bond oxidations and enantioselective epoxidation reactions.

\section{Experimental Section}

\section{General Catalytic Conditions}

A $20 \mathrm{~mL}$ vial was charged with: substrate $(0.36 \mathrm{mmol}$, 1 equiv.), catalyst (3.6 $\mathrm{mol}, 1 \mathrm{~mol} \%), \mathrm{CH}_{3} \mathrm{CN}(1.5 \mathrm{~mL})$. A $0.5 \mathrm{M} \mathrm{CH}_{3} \mathrm{CO}_{2} \mathrm{H}$ solution in $\mathrm{CH}_{3} \mathrm{CN}$ was added $(0.36 \mathrm{~mL}$, $0.18 \mathrm{mmol}, 50 \mathrm{~mol} \%$ ). The vial was cooled on an ice bath with stirring. Subsequently, a $1.0 \mathrm{M} \mathrm{H}_{2} \mathrm{O}_{2}$ solution in $\mathrm{CH}_{3} \mathrm{CN}$ (120 $\mathrm{mol} \%$ or $150 \mathrm{~mol} \%$ ) was delivered by syringe pump over 6-30 min. After the oxidant addition, the resulting mixture was stirred at $0{ }^{\circ} \mathrm{C}$ for another $10 \mathrm{~min}-2 \mathrm{~h}$. At this point, a $1.0 \mathrm{M}$ internal standard solution in $\mathrm{CH}_{3} \mathrm{CN}(0.36 \mathrm{~mL}$, $0.36 \mathrm{mmol}$ ) was added. The solution was diluted with $\mathrm{Et}_{2} \mathrm{O}$ to precipitate the iron complex, passed through a cotton wool filter to remove the catalyst. Subsequently, a sample was submitted to GC or NMR analysis. Reported analysis data represent the outcome of at least two independent catalysis experiments.

\section{Acknowledgements}

J. C. acknowledges the China Scholarship Council (CSC) for a doctoral scholarship. M. O. thanks the sustainability theme of Utrecht University for funding. The $X$-ray diffractometer has been financed by the Netherlands Organization for Scientific Research (NWO).

\section{References}

[1] a) C. Limberg, Angew. Chem. 2003, 115, 6112-6136; Angew. Chem. Int. Ed. 2003, 42, 5932-5954; b) M. Christmann, Angew. Chem. 2008, 120, 2780-2783; Angew. Chem. Int. Ed. 2008, 47, 2740-2742; c) L. Que, Jr., W. B. Tolman, Nature 2008, 455, 333-340; d) C.-L. Sun, B.-J. Li, Z.-J. Shi, Chem. Rev. 2011, 111, 1293-1314; e) M. Bordeaux, A. Galarneau, J. Drone, Angew. Chem. 2012, 124, 10870-10881; Angew. Chem. Int. Ed. 2012, 51, 10712-10723.

[2] a) E. I. Solomon, T. C. Brunold, M. I. Davis, J. N. Kemsley, S.-K. Lee, N. Lehnert, F. Neese, A. J. Skulan, Y.-S. Yang, J. Zhou, Chem. Rev. 2000, 100, 235-350; b) E. Y. Tshuva, S. J. Lippard, Chem. Rev. 2004, 104, 987-1012; c) M. Costas, M. P. Mehn, M. P. Jensen, L. Que, Jr., Chem. Rev. 2004, 104, 939-986.

[3] a) M. Costas, K. Chen, L. Que, Jr., Coord. Chem. Rev. 2000, 200-202, 517-544; b) W. Nam, Acc. Chem. Res. 2007, 40, 522-531; c) E. P. Talsi, K. P. Bryliakov, Coord. Chem. Rev. 2012, 256, 1418-1434.

[4] C. Kim, K. Chen, J. Kim, L. Que, Jr., J. Am. Chem. Soc. 1997, 119, 5964-5965.

[5] a) T. A. van den Berg, J. W. de Boer, W. R. Browne, G. Roelfes, B. L. Feringa, Chem. Commun. 2004, 25502551; b) A. Company, L. Gómez, M. Güell, M.; X. Ribas, J. M. Luis, L. Que, Jr., M. Costas, J. Am Chem. Soc. 2007, 129, 15766-15767; c) J. England, G. J. P. Britovsek, N. Rabadia, A. J. P. White, Inorg. Chem. 2007, 46, 3752-3767; d) J. England, C. R. Davies, M. Banaru, A. J. P. White, G. J. P. Britovseka, Adv. Synth. Catal. 2008, 350, 883-897; e) P. Liu, Y. Liu, E. L.-M. Wong, S. Xiang, C.-M. Che, Chem. Sci. 2011, 2, 21872195; f) Y. Hitomi, K. Arakawa, T. Funabiki, M. Kodera, Angew. Chem. 2012, 124, 3504-3508; Angew. Chem. Int. Ed. 2012, 51, 3448-3452; g) G. Olivo, O. Lanzalunga, S. Di Stefano, Adv. Synth. Catal. 2016, 358, 843-863.

[6] G. Olivo, O. Cussó, M. Costas, Chem. Asian J. 2016, 11, 3148-3158.

[7] M. S. Chen, M. C. White, Science 2007, 318, 783-787.

[8] E. A. Mikhalyovas, O. V. Makhlynets, T. D. Palluccio, A. S. Filatov, E. V. Rybak-Akimova, Chem. Commun. 2012, 48, 687-689.

[9] a) L. Gómez, I. Garcia-Bosch, A. Company, J. BenetBuchholz, A. Polo, X. Sala, X. Ribas, M. Costas, Angew. Chem. 2009, 121, 5830-5833; Angew. Chem. Int. Ed. 2009, 48, 5720-5723; b) I. Prat, L. Gómez, M. Canta, X. Ribas, M. Costas, Chem. Eur. J. 2013, 19, 1908-1913; c) G. Olivo, O. Lanzalunga, L. Mandolini, S. Di Stefano, J. Org. Chem. 2013, 78, 11508-11512; d) P. E. Gormisky, M. C. White, J. Am. Chem. Soc. 2013, 135, 14052-14055; e) L. Gómez, M. Canta, D. Font, I. Prat, X. Ribas, M. Costas, J. Org. Chem. 2013, 78, 1421-1433.

[10] D. Font, M. Canta, M. Milan, O. Cussó, X. Ribas, R. J. M. Klein Gebbink, M. Costas, Angew. Chem. 2016, 128, 5870-5873; Angew. Chem. Int. Ed. 2016, 55, 57765779.

[11] Q. Zhu, H. Huang, D. Shi, Z. Shen, C. Xia, Org. Lett. 2009, 11, 4536-4539. 
[12] a) K. Chen, L. Que, Jr., J. Am. Chem. Soc. 2001, 123, 6327-6337; b) M. Costas, L. Que, Jr. Angew. Chem. 2002, 114, 2283-2285; Angew. Chem. Int. Ed. 2002, 41, 2179-2181; c) V. A. Yazerski, P. Spannring, D. Gatineau, C. H. M. Woerde, S. M. Wieclawska, M. Lutz, H. Kleijn, R. J. M. Klein Gebbink, Org. Biomol. Chem. 2014, 12, 2062-2070.

[13] CCDC 1531774 (2) and 1531775 (3) contain the supplementary crystallographic data for this paper. These data can be obtained free of charge from The Cambridge Crystallographic Data Centre via www.ccdc.cam.ac.uk/data_request/cif.

[14] J. Serrano-Plana, W. N. Oloo, L. Acosta-Rueda, K. K. Meier, B. Verdejo, E. García-España, M. G. Basallote, E. Münck, L. Que, Jr., A. Company, M. Costas, J. Am. Chem. Soc. 2015, 137, 15833-15842.

[15] K. Suzuki, P. D. Oldenburg, L. Que, Jr., Angew. Chem. Int. Ed. 2008, 120, 1913-1915; Angew. Chem. Int. Ed.
2008, 47, 1887-1889. Structural data for $(S, S)-1$ is not available. Structural parameters for $(S, S)$ $\left[\mathrm{Fe}(\mathrm{BPBP})\left(\mathrm{CH}_{3} \mathrm{CN}\right)_{2}\right](\mathrm{SbF} 6)_{2}$ are very similar to those of $(\mathrm{S}, \mathrm{S})-1$

[16] K. Chen, M. Costas, J. Kim, A. K. Tipton, L. Que, Jr., J. Am. Chem. Soc. 2002, 124, 3026-3035.

[17] a) A. Company, L. Gómez, X. Fontrodona, X. Ribas, M. Costas, Chem. Eur. J. 2008, 14, 5727-5731; b) G. Olivo, M. Nardi, D. Vìdal, A. Barbieri, A. Lapi, L. Gómez, O. Lanzalunga, M. Costas, S. Di Stefano, Inorg. Chem. 2015, 54, 10141-10152.

[18] E. Vitaku, D. T. Smith, J. T. Njardarson, J. Med. Chem. 2014, 57, 10257-10274.

[19] J.-F. Biellmann, Chem. Rev. 2003, 103, 2019-2033.

[20] M. Canta, D. Font, L. Gõmez, X. Ribas, M. Costas, $A d v$. Synth. Catal. 2014, 356, 818-830. 